\title{
Neuroleptic Malignant Syndrome (NMS): A Rare Occurrence in Traumatic Brain Injury
}

\author{
Swapna Khanzode ${ }^{1 *}$ and PJ Giri ${ }^{2}$ \\ ${ }^{1}$ IDCC Critical care physician, Neuron Hospital, Dhantoli, Nagpur, India \\ ${ }^{2}$ Consultant Neurosurgeon, Neuron Hospital, Dhantoli, Nagpur, India
}

Submission: September 20, 2017; Published: November 27, 2017

*Corresponding author: Swapna Khanzode, DNB (Medicine), IDCC Critical care physician, KRIMS Hospital, Central Bazaar Road, Ramdaspeth, Nagpur 440010, India, Email: swapna.khanzode@gmail.com

\begin{abstract}
:
Neuroleptic malignant syndrome (NMS) is a rare, but potentially lethal emergency if undiagnosed. It is usually seen in patients with psychiatry illness on antipsychotics. NMS in traumatic brain injury is even more cryptic. Fifty percent of traumatic brain injury patients have post traumatic agitation and emotional disorders .Haloperidol is most preferred drug in post traumatic agitation. Haloperidol is incidentally the most common medication that can cause NMS. It is difficult to diagnose NMS in patients with traumatic brain injury as signs and symptoms can be overlapping with the native brain injury.

We present the case of a young male with a history of road traffic accident with diffuse axonal injury that eventually developed NMS after he received $15 \mathrm{mg}$ of haloperidol in divided doses over 24 hours. He was successfully treated with dantrolene sodium, bromocriptine, aggressive hydration and ventilatory support. The patient responded well to treatment and was eventually discharged. A high index of suspicion is required to diagnose NMS in traumatic brain injury patients. Clinical signs like high grade fever, rigidity, deranged renal functions and elevated serum CPK levels are all clues to diagnosis.
\end{abstract}

Abbreviations: NMS: Neuroleptic Malignant Syndrome; TBI: Traumatic Brain Injury; ECT: Electroconvulsive Therapy

\section{Introduction}

\section{Case}

18 year old male involved in road traffic accident was admitted to ICU with history of altered sensorium, convulsions and vomiting. On examination, he was hemodynamically stable, Glasgow Coma Scale score was 8/15, and pupils were bilaterally equal and reacting to light. No cervical spine injury was detected. CT scan brain was suggestive of diffuse axonal injury and mild cerebral edema. Neurosurgical opinion was sought and conservative treatment was planned. There were no long bone injuries and other systems were also within normal limits. Laboratory investigations were normal except mild leukocytosis. The patient was managed conservatively with anti edema measures, anticonvulsants, antibiotics and supportive care. Patient was intubated as patient was drowsy due to traumatic brain injury.

On the second day of admission, patient was hemodynamically stable, but extremely irritable. In view of persistent irritability, the patient received $15 \mathrm{mg}$ of haloperidol over 24 hours. Haloperidol is the preferred drug in post traumatic agitation as there is minimal effect on respiration and conscious level [1]. 24 hours later [day 3 of admission], patient developed hectic spikes of fever, became tachycardia, tachypnoeic with labile blood pressure. Patient's GCS score dropped to 3/15 and he developed rigidity in all four limbs. There was no obvious source of infection. Laboratory investigations revealed leukocytosis [total leukocyte count 29,200 ] and renal functions were deranged (blood urea- 80, serum creatinine $-2.3 \mathrm{mg} / \mathrm{dl}$ ). Arterial blood gas report revealed severe metabolic acidosis, but lactates were normal. Subsequent MRI did not reveal any increase in mass effect or hydrocephalus. Serum CPK levels were very high (CPK- 50,230U/L). Infective work up was negative. All cultures were sterile.

Diagnosis of Neuroleptic malignant syndrome (NMS) was established. Haloperidol was promptly stopped and respiratory support in the form of mechanical ventilation was initiated. Aggressive fluid resuscitation, aggressive pharmacological and surface cooling measures were adopted. Patient was treated with dantrolene sodium $3 \mathrm{mg} / \mathrm{kg}$ and bromocriptine $2.5 \mathrm{mg}$ thrice daily through nasogastric tube. He responded well to the treatment and 
his fever started settling down after 72 hours of treatment. Renal parameters improved with aggressive hydration. By fifteenth day of admission, muscle tone improved significantly, sensorium was better and the patient was weaned off successfully from the ventilator. Dantrolene sodium and bromocriptine were tapered and stopped by twenty first day. He was subsequently shifted to ward and discharged after decannulation of tracheostomy tube.

\section{Discussion}

Neuroleptic malignant syndrome (NMS), first described nearly five decades ago, is an idiosyncratic, life-threatening complication of treatment with antipsychotic drugs that is characterized by fever, severe muscle rigidity, autonomic dysfunction and mental status changes [2]. Incidence of post traumatic agitation is quite high in patients with traumatic brain injury (TBI). Almost fifty percent of TBI patients suffer from emotional disorders and irritability [3]. Haloperidol is the preferred antipsychotic in these settings owing to minimal effect on respiration and sensorium [1]. Incidentally, haloperidol is also the most common drug causing NMS.

Dopamine is essential neurotransmitter in maintaining autonomic cardiovascular stability and regulating hypothalamic thermostat. It also plays an important role in maintaining the conscious level, and normal muscle tone. Antipsychotic-induced dopamine blockade plays a pivotal triggering role in NMS [4]. In addition, traumatic brain injury patients have diffuse axonal injury which further leads to decreased dopamine neurotransmission. This combined effect leads to hypodopaminergic state and causes signs and symptoms of NMS $[5,6]$.

It is difficult to diagnose NMS in patients with traumatic brain injury as signs and symptoms can be overlapping with the native brain injury. CPK levels, leukocytosis can be associated with blunt trauma. Hence careful review of drug history, negative infective work up and exclusion of worsening brain injury are needed to diagnose NMS in head injury patients. Clinical features of NMS are described in Table 1. The presence of all three major, or two major and four minor, manifestations indicates a high probability of the presence of neuroleptic malignant syndrome, if supported by clinical history. Treatment of NMS begins with prompt stoppage of neuroleptic agent. Aggressive hydration, temperature control and correction of electrolytes are the mainstay of treatment [7].

Table 1: Clinical features of NMS are described.

\begin{tabular}{|c|c|}
\hline Category & Manifestations \\
\hline Major & $\begin{array}{l}\text { Fever, rigidity, elevated creation phosphokinase } \\
\text { concentration }\end{array}$ \\
\hline Minor & $\begin{array}{l}\text { Tachycardia, abnormal arterial pressure, tachypnoea, } \\
\text { altered consciousness, diaphoresis, leucocytosis }\end{array}$ \\
\hline
\end{tabular}

In Caroff's review of sixty cases, supportive therapy was the predominant treatment modality [8]. Dantrolene sodium is a direct skeletal muscle relaxant, typical daily dose is 1 to $3 \mathrm{mg}$ per kg per day intravenous and the maximum dose is $10 \mathrm{mg}$ per $\mathrm{kg}$ per day. Its action starts within minutes of administration and causes reduction in rigidity and heat production. It is commonly given for ten days. Its dose should be tapered before stopping. Bromocriptine is a dopamine agonist; it restores the lost dopaminergic tone. To start with, it is given in the dose of $2.5 \mathrm{mg}$ every six to eight hours orally or through nasogastric tube and can be titrated to a maximum dose of $40 \mathrm{mg}$ per day. It should be continued for 10 days after the control of NMS and should be tapered before stopping $[9,10]$.

Other drugs like amantadine and clonidine have also been tried. Treatment of complications like renal failure might warrant renal replacement therapy. Electroconvulsive therapy (ECT) is required in NMS patients with catatonia, patients not responding to the medical therapy [9]. Literature about NMS associated with head injury patients is limited only to the case reports [11]. The main reason being difficulty in diagnosis as clinical features overlap with TBI. In a case series on NMS, nine cases of are reported with use of haloperidol in the traumatic brain injury patients [3] (Figure 1). Younger patients are at higher risk for the development of NMS and it is twice more common in males. The reported incidence of NMS with use of haloperidol is ranging from 0.02 to $12.2 \%$ [3].

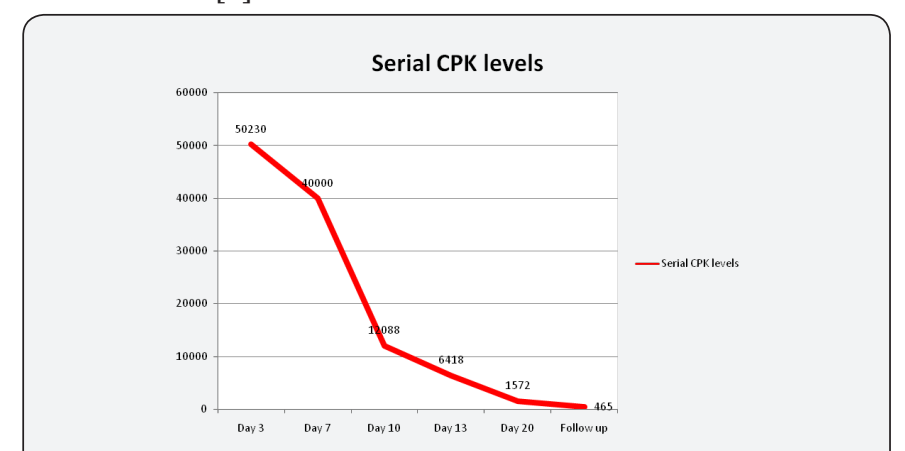

Figure 1: Serial CPK Levels.

\section{Conclusion}

Diagnosis of NMS in TBI patients is difficult as signs and symptoms may overlap with native brain injury. NMS should be suspected if there is history of use of haloperidol for post traumatic agitation, following which there is development of fever, rigidity, and worsening level of consciousness and very high CPK levels. At the same time, it is important to rule out sepsis and neuroimaging should be done to rule out any new lesions or worsening of initial brain injury. NMS is a potentially life threatening emergency. Early recognition and aggressive supportive treatment along with specific medications leads to better outcome and decreased mortality. As haloperidol is the most widely used medication for post traumatic agitation, neurosurgeons and intensivists should be aware of NMS [12].

\section{Referencces}

1. Bellamy CJ, Kane Gill, Sandra L, Falcione BA, Seybert AL (2000) Neuroleptic malignant syndrome in traumatic head patients treated with haloperidol. J Trauma 66: 954-658. 
2. Jeffrey R Strawn, Paul E Keck, Stanley N Caroff (2007) Neuroleptic Malignant Syndrome. Am J Psychiatry 164: 870-876.

3. Mysiw WJ, Sandel MI (1997) The agitated brain injury patients, Part II. Pathophysiology and treatment. Arch phys Med Rehabil 78(2): 213220

4. Mann SC, Caroff SN, Fricchione G, Campbell EC (2000) Central dopamine hypoactivity and the pathogenesis of the neuroleptic malignant syndrome. Psychiatr Ann 30(5): 363-374.

5. Kadyan V, Colachis SC, Depalma MJ, Sanderson JD, Mysiw WJ (2003) Early recognization neuroleptic malignant syndrome during truamtic brain injury rehabiltation. Brain Inj 17(7): 631-637.

6. Levenson JL (1985) Neuroleptic malignant syndrome. Am J Psychiatr 142: 1137-1145.

7. Adnet P, Lestavel P, Krivosic Horber R (2000) Neuroleptic malignant syndrome. Br J Anaesth 85: 129-135.
8. Caroff SN (1980) The neuroleptic malignant syndrome. J Clin Psychiatr 41: 79-83.

9. Nissar Shaikh, Ghanem Al Sulaiti, Abdel Nasser, Muhammad Ataur Rahman (2011) Neuroleptic malignant syndrome and closed head injury: A case report and review. Asian J Neurosurg 6(2): 101-105.

10. Bhanushali MJ, Tuite PJ (2004) The evaluation and management of patients with neuroleptic malignant syndrome. Neurol Clin 22(2): 389-411.

11. Wilkinson R, Meythaler JM, Guin-Renfroe S (1999) Neuroleptic malignant syndrome induced by haloperidol following traumatic brain injury. Brain Inj 13(12): 1025-1031.

12. Vincent FM, Zimmerman JE (1986) Neuroleptic malignant syndrome complicating head injury. Neurosurg 18(2): 190-193.

\section{Your next submission with Juniper Publishers} will reach you the below assets

- Quality Editorial service

- Swift Peer Review

- Reprints availability

- E-prints Service

- Manuscript Podcast for convenient understanding

- Global attainment for your research

- Manuscript accessibility in different formats

( Pdf, E-pub, Full Text, Audio)

- Unceasing customer service

Track the below URL for one-step submission https://juniperpublishers.com/online-submission.php 